\title{
INFLUENCE OF THE QUALITY OF FUEL ATOMIZATION ON THE EMISSION OF EXHAUST GASES TOXIC COMPONENTS OF COMBUSTION ENGINES
}

\author{
WPLYW JAKOŚCI ROZPYLENIA PALIWA NA \\ EMISJĘ TOKSYCZNYCH SKLADNIKÓW SPALIN \\ SILNIKÓW SPALINOWYCH
}

\author{
Antoni Jankowski, Mirosław Kowalski \\ Instytut Techniczny Wojsk Lotniczych \\ e-mail:antoni.jankowski@itwl.pl,miroslaw.kowalski@itwl.pl
}

\begin{abstract}
Abstact: The paper contains analysis of the impact on the quality of the fuel spray of droplets on the number and the value of the surface area of the droplets that have a direct impact on the efficiency of the combustion process. It presents a change in the level of toxic exhaust emissions with an increase in the so-called. Sauter Mean Diameter (SMD) of fuel droplets. The presented figures show that the increase in the average droplet diameter SMD in particular causes an increase of toxic exhaust gases emissions, i.e. mainly nitrogen oxides $\mathrm{NO}$, carbon monoxide CO, hydrocarbons $\mathrm{HC}$ and Particulate Matter (PM). This tendency is not constant, because it is changing according to changes of the coefficient of equivalence $\Phi$. For example, emissions of nitrogen oxides for the lean mixtures $(\Phi<1)$, with an increase in average droplet diameter increases, while now for the rich mixtures $(\Phi>1)$, this trend is significantly changed, i.e. the level of this emission decreases.
\end{abstract}

Keywords: combustion engines, fuel atomizing, air pollution, environmental protection

Streszczenie: $W$ artykule podjęto się analizy wphywu jakości rozpylanego paliwa na uzyskiwana liczbe kropel w strudze oraz na uzyskiwana wartość pola powierzchni kropel, które maja bezpośredni wphyw na efektywność procesu spalania. Przedstawiono jak zmienia się wielkość emisji toksycznych składników spalin ze wzrostem tzw. średniej średnicy Sautera (SMD) kropel paliwa. Prezentowane rysunki pokazahy, że wzrost średniej średnicy kropel SMD w zasadzie wywotuje wzrost emisji toksycznych składników spalin, tj. głównie tlenków azotu $N O$, tlenku węgla CO, węglowodorów HC oraz cząstek statych (sadzy). Ten trend nie jest jednak stahy, gdyz ulega ona zmianom wraz ze zmianami wartości wspótczynnika równoważności $\Phi$. Na przykład emisja tlenków azotu dla mieszanek ubogich $(\Phi<1)$, wraz ze wzrostem średnich średnic kropel wzrasta, zaś już dla mieszanek bogatych $(\Phi>1)$ ta tendencja ulega istotnej zmianie, tzn. poziom tej emisji maleje.

Stowa kluczowe: silniki spalinowe, rozpylanie paliwa, zanieczyszczenie powietrza, ochrona środowiska 
Influence of the quality of fuel atomization on the emission of exhaust gases toxic... Wplyw jakości rozpylenia paliwa na emisje toksycznych sktadników spalin...

\section{Wprowadzenie}

Zużycie paliwa i emisja toksycznych składników spalin są głównymi tematami badań konstruktorów silników spalinowych i decydują o postępie w konstrukcji i eksploatacji tych silników. Głównymi powodami nadmiernego zużycia paliwa i emisji toksycznych składników spalin jest niedokładne odmierzanie paliwa oraz niewłaściwe przygotowanie mieszanki palnej. Wynika to $\mathrm{z}$ dość słabego rozpoznania mechanizmu przygotowania mieszanki palnej, a właściwe odmierzenie paliwa oraz przygotowanie mieszanki palnej jest bezpośrednio uzależnione od procesu rozpylenia paliwa. $Z$ praktycznego punktu widzenia, pod pojęciem rozpylania paliwa należy rozumieć jego rozpad na małe lub bardzo małe krople. Zachodzi to najczęściej przy dużej prędkości wypływu paliwa - tj. około $100 \mathrm{~m} / \mathrm{s}$. Rozpad paliwa na krople przebiega łatwiej, jeżeli ciecz występuje $\mathrm{w}$ formie podatnej na rozpad. Najbardziej podatne są cienkie strugi lub błony paliwa, gdyż w obu tych formach energia powierzchniowa jest największa, a przez to największa jest też ich niestateczność. Wynika z tego, że zadaniem rozpylaczy jest przede wszystkim wytworzenie strug lub błon paliwa. Proces rozpylenia paliwa uzależniony jest przede wszystkim od: ciśnienia wtrysku, prędkości, kształtu strugi i przebiegu wtrysku oraz od ruchu powietrza w komorze spalania. $\mathrm{Z}$ tego też powodu koniecznym jest rozpatrzenia jakości rozpylania paliwa podawanego do komory spalania na emisję toksycznych składników spalin, głównie w odniesieniu do paliw węglowodorowych, stosowanych aktualnie dla większości silników spalinowych.

\section{Wpływ rozpylenia paliwa na emisję składników toksycznych}

Wyniki badań wskazują, że dla jakości spalania decydujące znaczenie ma rozpylenie paliwa. Wynika to $\mathrm{z}$ tego, że procesami spalania mieszanek dwufazowych rządzą procesy fizyczne przebiegające najwolniej. Takim procesem jest przede wszystkim parowanie. Prędkość odparowania ciekłych kropel jest wprost proporcjonalna do jakości rozpylenia. W badaniach rozpylonej strugi paliwa, bardzo ważnym jest wiedza dotycząca wielkości i widma rozkładu kropel oraz ich prędkości w strudze paliwa. Krople natomiast maja różne średnice, w zależności od warunków wypływu i właściwości paliwa. $\mathrm{Na}$ potrzeby prowadzenia analizy procesu rozpylenia paliwa (tworzenia strugi) i procesu spalania w komorze spalania, korzystniej jest posługiwać się nie zbiorem kropel W różnych średnicach, a kroplą o stałej średniej średnicy, charakterystycznej dla danych warunków wypływu. W literaturze przedmiotu podaje się kilka takich umownych średnic kropel, z których najbardziej popularna jest średnia średnica Sautera (SMD - Sauter mean diameter, $d_{32}$ ), definiowana jako [2]:

$$
d_{32}=\frac{\sum_{i=1}^{n} c_{i} d_{i}^{3}}{\sum_{i=1}^{n} c_{i} d_{i}^{2}}
$$

gdzie: $c_{i}$ - liczba kropel o danej średnicy,

$d_{i} \quad$ - średnica i-tej kropli. 
Średnia średnica Sautera (SMD) jest określana ze stosunku sumy objętości do sumy powierzchni kropel i jest stosowana do analizy procesów wymiany ciepła i masy.

Czas wymagany do odparowania masy wtryśniętego paliwa jest zależny od stosunku powierzchni do objętości cieczy. Można przyjąć, że silnik w tryskiem bezpośrednim GDI (Gasoline Direct Injection - bezpośredni wtrysk benzyny) pracujący $\mathrm{w}$ sposób ustalony, przy małych obciążeniach musi mieć wtryśnięte w przybliżeniu $10 \mathrm{mg}$ benzyny do każdego cylindra, na jeden cykl. Powierzchnia kropel paliwa zależy od poziomu rozpylenia. Na przykład dla pojedynczej kropli o średnicy $2,98 \mathrm{~mm}(2980 \mu \mathrm{m})$ powierzchnia wyniesie $28 \mathrm{~mm}^{2}$. Jeżeli ta sama ilość paliwa zostanie rozpylona do poziomu, który jest osiągany we współczesnych silnikach PFI (Port Fuel Injection - wielopunktowy wtrysk paliwa do kolektora dolotowego), tzn. około $100 \mu \mathrm{m}$ SMD, to powstanie około $26000 \mathrm{kropel}$ o powierzchni całkowitej 30 razy większej niż powierzchnia tej pojedynczej kropli. Silniki GDI pracujące z ładunkiem uwarstwionym wymagają rozpylenia na krople o średnicy Sautera SMD poniżej $25 \mu \mathrm{m}$. Oznacza to około 600000 kropel o powierzchni 85 razy większej niż powierzchnia pojedynczej kropli. Na wykresie (rys. 1) poprowadzono pionową linię przy SMD $15 \mu \mathrm{m}$, która odpowiada rozpyleniu niezbędnemu do zapewnienia efektywnego spalania w silniku GDI. Typowa struga rozpylonego paliwa dla silnika GDI, zawierająca $10 \mathrm{mg}$ benzyny na cykl, powinna więc być rozpylana na około 8 milionów kropel o całkowitym polu powierzchni 200 razy większym niż pole powierzchni pojedynczej kropli. Takie pole powierzchni jest wystarczające do tego, aby odparowanie paliwa nastąpiło w czasie 5 do $8 \mathrm{~ms}$, który jest dostępny między wtryskiem a zapłonem.

Rozpylenie $10 \mathrm{mg}$ paliwa na 26 milionów kropel wymaga zastosowania w systemie Common Rail ciśnienia wtrysku około $20 \mathrm{MPa}$.

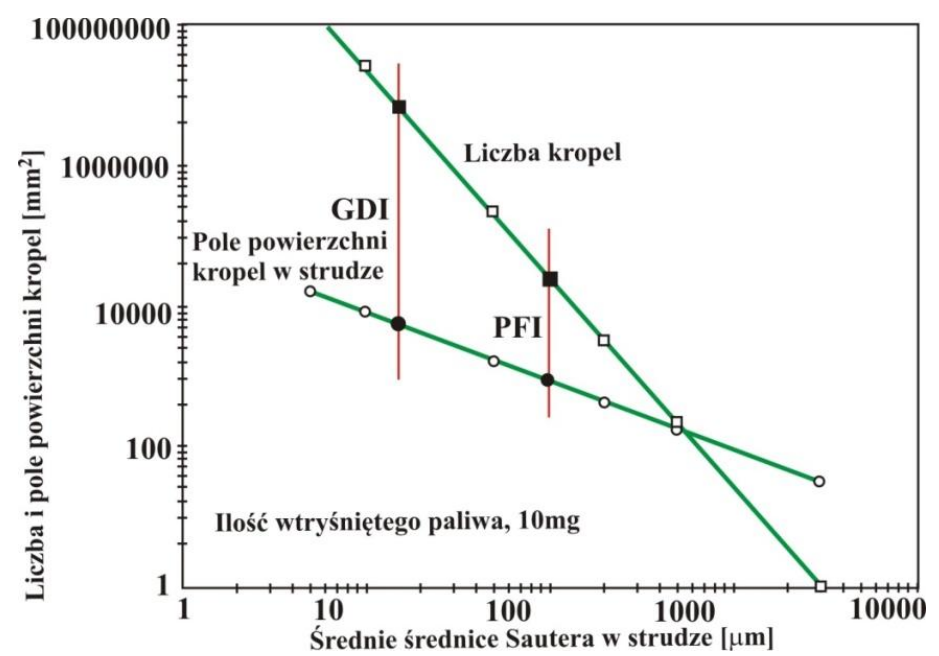

Rys. 1 Zależność pola powierzchni kropel i liczby kropel od średniej średnicy Sautera przy wtrysku paliwa o masie $10 \mathrm{mg}$ w jednym cyklu. Linie pionowe oznaczaja wymagane SMD kropel w odniesieniu do silników GDI i PFI [6] 
Influence of the quality of fuel atomization on the emission of exhaust gases toxic... Wplyw jakości rozpylenia paliwa na emisje toksycznych sktadników spalin...

$\mathrm{Na}$ rys. 2 - 5 przedstawiono wpływ rozpylenia paliwa na emisję różnych składników toksycznych. Na rys. 2 przedstawiono wpływ średniej średnicy Sautera (SMD) kropel w strudze na emisję NO, w funkcji współczynnika równoważności $\Phi$.

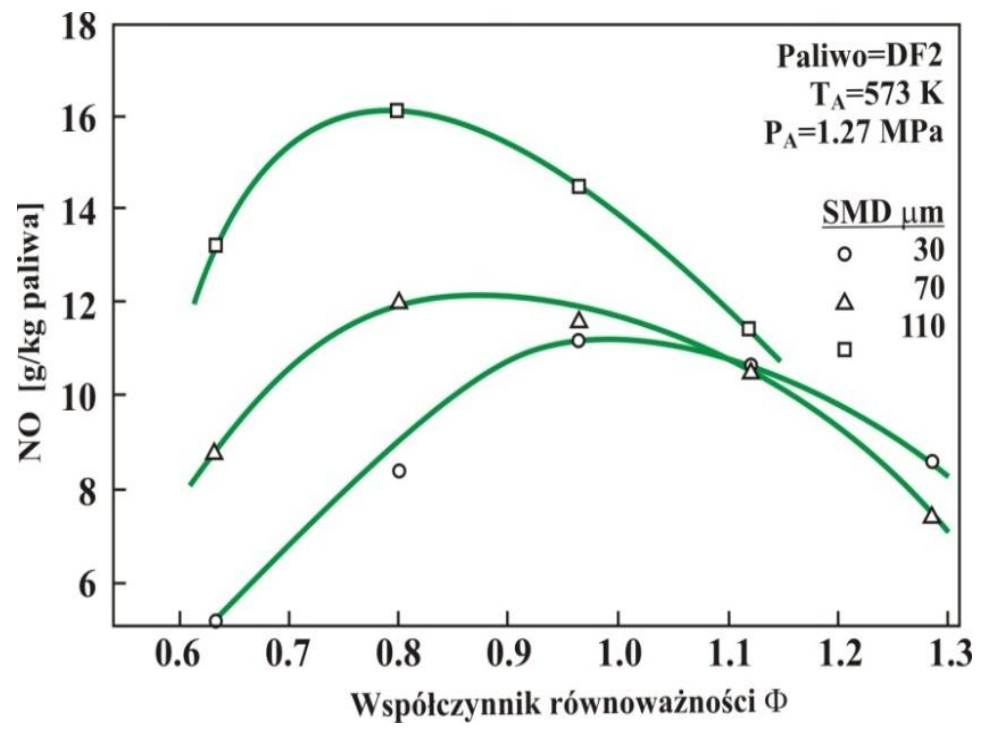

Rys. 2 Wptyw średnicy Sautera SMD kropel paliwa na emisję tlenku azotu [1]

Emisja NO jest silnie zależna od wartości współczynnika równoważności $\Phi$, który jest jednym $\mathrm{z}$ najważniejszych parametrów mających bezpośredni wpływ na toksyczność spalin. Jest on wyrażany stosunkiem ilości paliwa do powietrza $\mathrm{w}$ danej mieszance, do stosunku paliwa do powietrza $\mathrm{w}$ mieszance stechiometrycznej.

$$
\Phi=\frac{(F / A)_{a}}{(F / A)_{s}}
$$

gdzie: $(F / A)_{a} \quad-\quad$ aktualny stosunek paliwa do powietrza,

$(F / A)_{s} \quad$ - stosunek stechiometryczny.

Mniejsze od jedności wartości $\Phi$ oznaczają ubogą mieszankę, a wartości większe mieszankę bogatą. O ile w zakresie ubogich mieszanek $\Phi<1$ największa emisja powstaje przy dużych wartościach SMD, to przy bogatej mieszance różnice w emisji NO są mało zależne od średnicy kropel. Jest to spowodowane spalaniem o charakterze dyfuzyjnym dużych kropel przy lokalnym stosunku paliwa do powietrza bliskim stechiometrycznemu. Lokalnie tworzy się wysoka temperatura i stąd powstają duże ilości NO. Zmniejszenie średnicy kropel hamuje ten proces, a więc większa część procesu spalania będzie przebiegała w jednorodnej 
mieszance, w której jest mniejsza prędkość generowania NO. Nawet przy bardzo niskich wartościach współczynnika równoważności (uboga mieszanka), kiedy średnia temperatura jest niska, obecność dużych kropel w strefie spalania powoduje powstanie warunków, w których w miejscu spalania jest mieszanka bliska stechiometrycznej i w wyniku tego tworzą się duże ilości NO.

$\mathrm{Na}$ rys. 3 przedstawiono wpływ średnicy kropel SMD w strudze na emisję CO, w funkcji wartości współczynnika równoważności.

$\mathrm{Z}$ analizy rysunku wynika, że przy mniejszej średnicy kropel, a więc krótszym czasie odparowania, uzyskuje się zmniejszenie emisji $\mathrm{CO}, \mathrm{z}$ wyjątkiem obszaru o bardzo niskich wartościach współczynnika równowagowego, w którym to zmniejszenie jest mniej wyraźne. Jest to spowodowane tym, że wzrost prędkości parowania przy małych wartościach współczynnika równoważności, wynikający z redukcji średnicy kropel, ma mniejszy wpływ na spalanie. W mieszance panuje bowiem niedobór powietrza, a więc decyduje prędkość reakcji chemicznych.

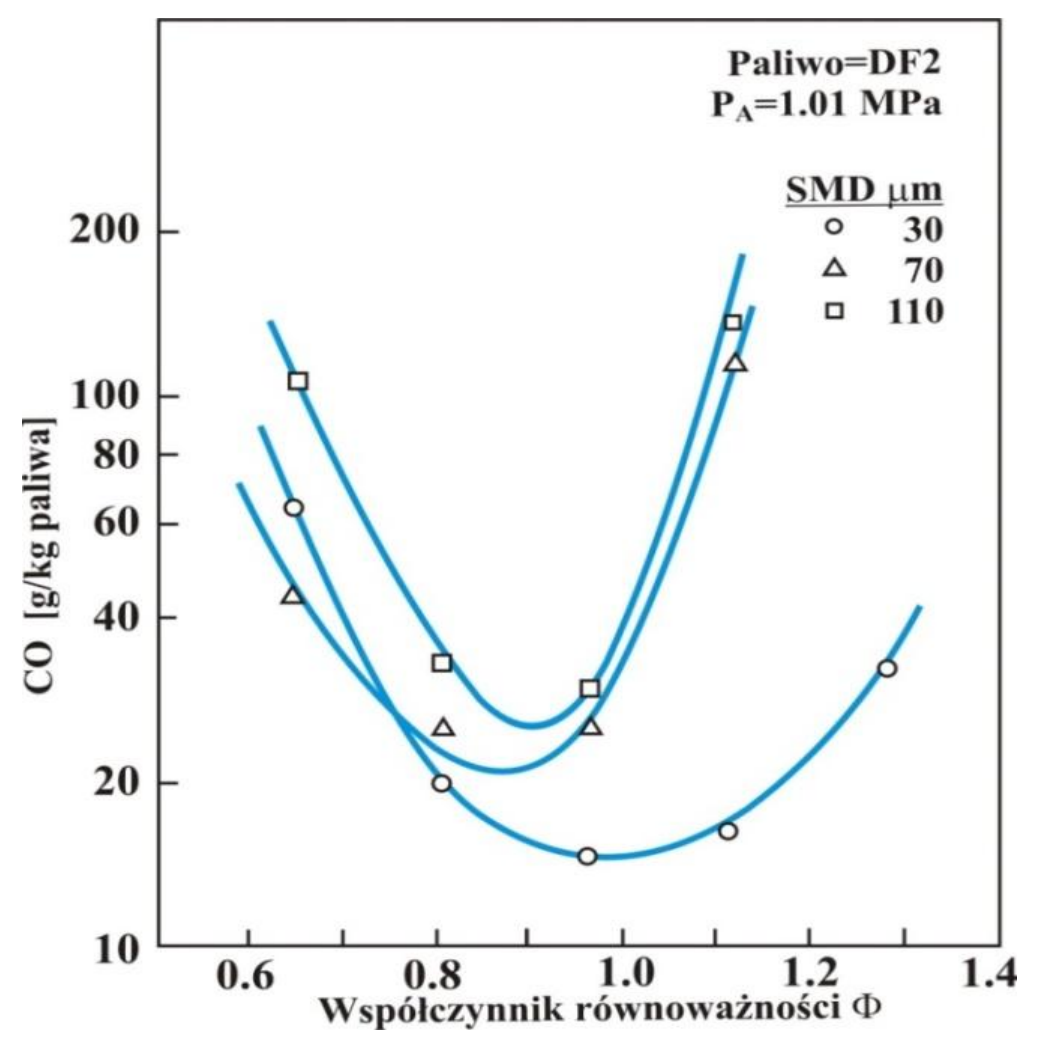

Rys. 3 Wplyw SMD kropel paliwa na emisję tlenku węgla [2] 
Influence of the quality of fuel atomization on the emission of exhaust gases toxic... Wplyw jakości rozpylenia paliwa na emisje toksycznych sktadników spalin...

Na rys. 4 przedstawiono wpływ SMD kropel w strudze w funkcji wartości współczynnika równoważności na emisję HC.

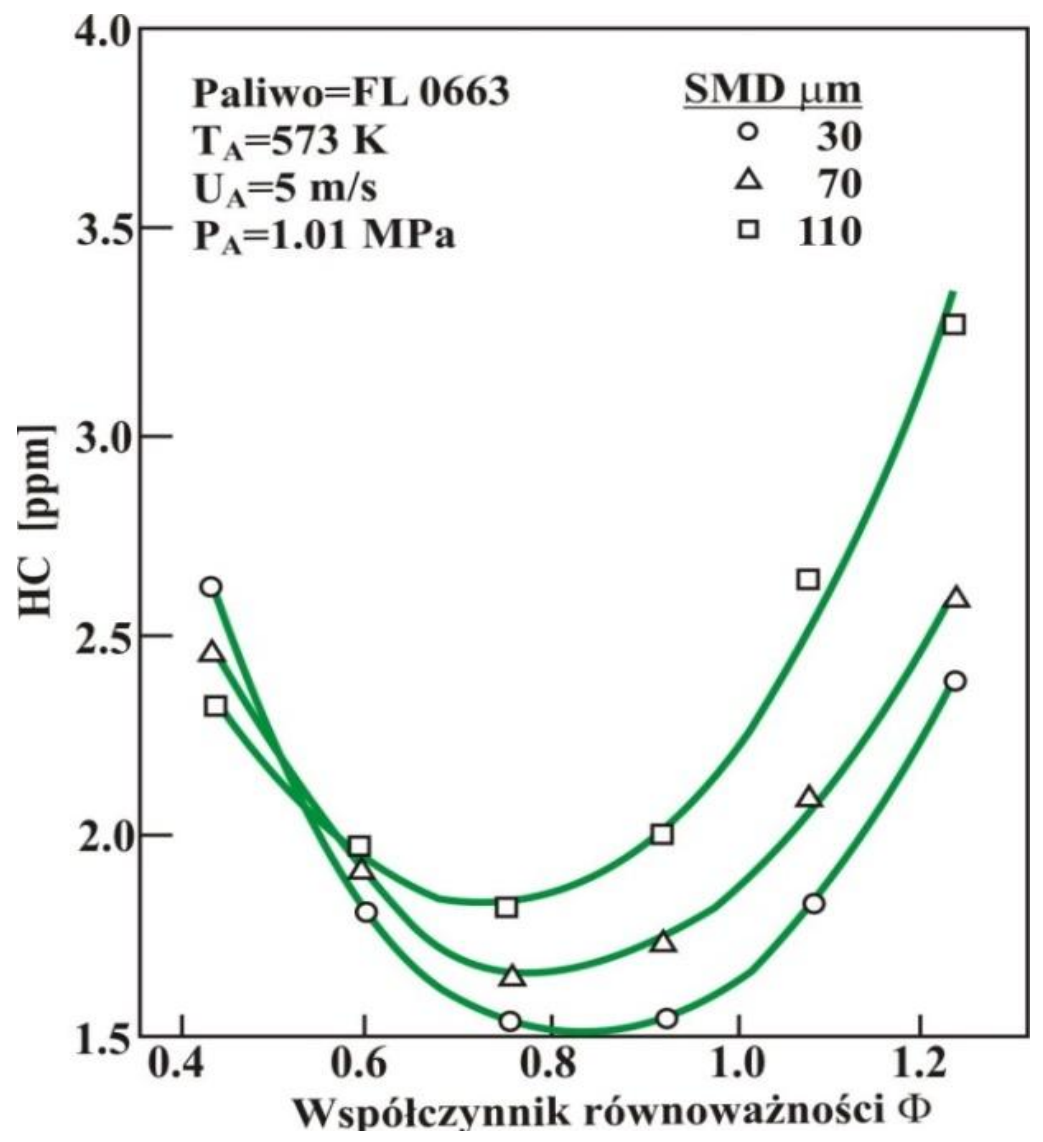

Rys.4 Wplyw SMD kropel paliwa na emisję węglowodorów [2]

Przebieg krzywych wskazuje, że ten wpływ jest podobny jak w przypadku emisji $\mathrm{CO}$; zmniejszenie średnicy SMD kropel powoduje zmniejszenie emisji HC, co jest szczególnie wyraźnie widoczne w zakresie wartości współczynnika równoważności większego od stechiometrycznego, czyli w zakresie bogatych mieszanek. W zakresie małych wartości współczynnika równoważności, czyli mieszanek ubogich ten wpływ nie jest jednoznaczny. Zagęszczenie linii w zakresie wartości współczynnika równoważności mniejszych od stechiometrycznego jest spowodowane łatwiejszym dostępem do tlenu, a więc proces parowania ma tu mniejszy wpływ na ilość wyemitowanych HC. 
$\mathrm{Na}$ rys. 5 przedstawiono wpływ SMD kropel w strudze w funkcji wartości współczynnika równoważności na emisję cząstek stałych.

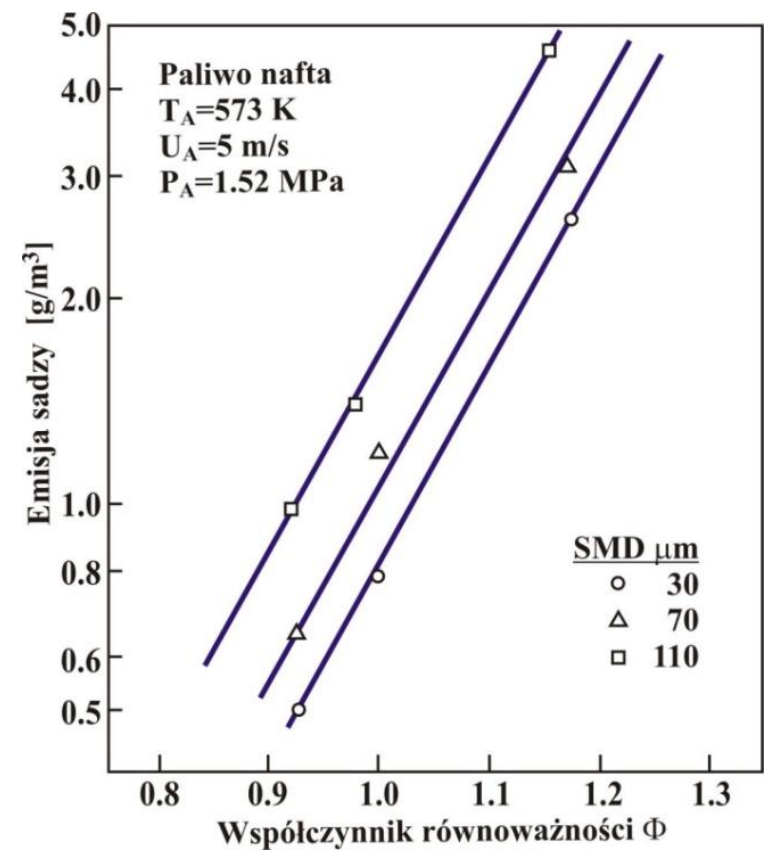

Rys. 5 Wplyw kropel paliwa SMD na emisję sadzy [5]

Wykres pokazuje zawartość cząstek stałych w skali logarytmicznej, z którego wynika niemal liniowy wzrost zawartości cząstek stałych wraz ze wzrostem współczynnika równoważności $\Phi$. Zwiększenie średnich średnic SMD powoduje, że liczba cząstek stałych, przy tej samej wartości współczynnika równoważności, rośnie, co jest efektem parowania kropel.

\section{Podsumowanie}

Tak więc proces rozpylenia paliwa, jego jakość, jest bardzo istotna z punktu widzenia emisji składników toksycznych spalin. W dodatku stwierdzono, że wzrost średnich średnic Sautera SMD powoduje istotne zmniejszanie się liczby kropel w strudze oraz zmniejszenie ich pola powierzchni.

Dane przedstawione na rys. 2 - 5 wskazują najogólniej, że wzrost średnich średnic kropel (SMD) w strudze rozpylonego paliwa powoduje wzrost emisji NOx, CO, HC i cząstek stałych. Nie jest to jednak jednoznaczne, gdyż w zależności od wartości współczynnika równoważności $\Phi$, trend ten ulega zmianom.

Ostatecznie należy stwierdzić, że wskazanym jest prowadzenie badań jakości rozpylanego paliwa, gdyż pozwala to na istotną poprawę efektywności procesu spalania przy jednoczesnym obniżaniu emisji toksycznych składników spalin. 
Influence of the quality of fuel atomization on the emission of exhaust gases toxic... Wplyw jakości rozpylenia paliwa na emisje toksycznych sktadników spalin...

\section{Literatura}

[1] Cernej A., Dobovisek Z., Jankowski A.: Fundamental Study on NOX Emission Abated by Flue Gas Recirculation (FGR), Journal of Polish CIMAC, Vol. 1, No. 1, pp. 51-63, Science Publication of Polish National Committee of CIMAC, Warszawa 1994.

[2] Jankowski A.: Studium wplywu ciśnienia, prędkości i rodzaju strugi gazów na przebieg procesu spalania. Wyd. ITWL, ISSUE NO. 28, Warszawa 2010.

[3] Jankowski A., Sandel A., Sęczyk J., Siemińska-Jankowska B.: Some Problems of Improvement of Fuel Efficiency and Emissions in Internal Combustion Engines, Journal of KONES. Internal Combustion Engines. Vol. 9, No. 1-2, s. 333-356, Wyd. Permanent Committee of KONES, Warszawa 2002.

[4] Kowalewicz A.: Podstawy procesów spalania, Wyd. WNT, ISBN 8320424968, 2000.

[5] Won H. W., Sharma A., Moon S. E., Vanegas A. Peters N.: An Experimental Study of Cluster Nozzles for DI Diesel Engine, SAE Paper 2009-24-0053, 2009.

[6] Zhou F., Harrington D. L., Lai M-C.: Automotive Gasoline Direct Injection Engines, SAE-R-315, 2002.

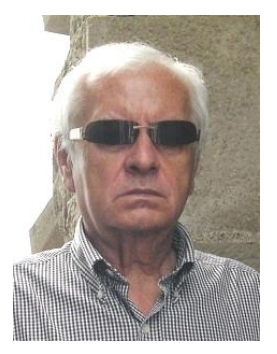

prof. dr hab. inż. Antoni Jankowski jest absolwentem Wydziatu MEL Politechniki Warszawskiej, gdzie uzyskat stopień magistra inż. $\quad w$ specjalności silniki lotnicze oraz doktora nauk technicznych. Obecnie pracuje $w$ Instytucie Lotnictwa i Instytucie Technicznym Wojsk Lotniczych, gdzie uzyskat stopień dr. hab. W roku 2013 uzyskat tytut naukowy prof. nauk technicznych. Obszar jego zainteresowań naukowych, to: budowa i eksploatacja maszyn, w tym silniki spalinowe, procesy spalania i ekologia środków transportu, inżynieria materiałowa. W dorobku ma ok. 200 publikacji naukowych, w tym 17 patentów, $w$ tym 1 patent na silnik Meteor 2 do rakiety, która przekroczyła granice kosmosu, oraz ma około 200 opracowań naukowo-technicznych w większości wdrożonych do praktyki. Byt i jest polskim delegatem do światowych organizacji naukowych CIMAK i FISITA, organizatorem licznych konferencji i kongresów naukowych. Jest recenzentem $i$ promotorem prac doktorskich $i$ habilitacyjnych.

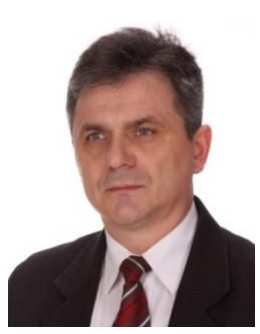

dr hab. inz. Mirostaw Kowalski, prof. nadzw. jest absolwentem Wojskowej Akademii Technicznej w Warszawie, która ukończyt w 1987 roku. Pracuje w Instytucie Technicznym Wojsk Lotniczych $w$ Warszawie na stanowisku Zastępcy Dyrektora ITWL ds. Organizacyjno-Technicznych oraz w Wyższej Szkole Oficerskiej Sit Powietrznych w Dęblinie na stanowisku profesora nadzwyczajnego. Gtówne obszary działalności to teoria, konstrukcje i diagnostyka lotniczych zespołów napędowych. 